\title{
The enigma of dust provenance: where else does Antarctic dust come from?
}

Paul Vallelonga

\begin{abstract}
It has been shown that most, but not all, of the dust in Antarctica originates from Southern South America. Where else does dust come from? I review the evidence for dust provenance from Australia and within Antarctica.
\end{abstract}

Since the 1990's, there has been clear and increasingly unequivocal evidence that the majority of dust in Antarctica originates from Southern South America (SSA), particularly Patagonia and likely also the Puna/Altiplano region. The key method for attributing dust sources is radiogenic isotope geochemistry: the identification of characteristic isotopic ratios of Strontium (Sr), Neodymium (Nd) and Lead $(\mathrm{Pb})$ (Delmonte et al. 2008; Vallelonga et al. 2010), which vary due to the different ages and geochemical compositions of their source rock material on each continent. There is a clear match between the isotopic signatures of Antarctic ice from the dust-rich Last Glacial Maximum (LGM) and loess samples taken from SSA dust deflation zones as well as lofted dust collected from the atmosphere.

\section{Multiple isotopic fingerprints}

Although the precise number and locations of the contributing dust sources are still debated, it is clear that most LGM dust in Antarctic ice strata originates from South America. It is much more difficult, however, to identify dust sources during the interglacials. One difficulty is that interglacial Antarctic dust fluxes are up to 25 times lower than LGM fluxes (Lambert et al. 2008), so much larger sample sizes are needed to analyze the dust.

Another problem lies in the difficulty of distinguishing minor isotopic source signatures. $\mathrm{Sr}$ and $\mathrm{Nd}$ isotopic signatures found in ice reflect a mixture between multiple sources - the more significant the major source is, the more difficult it is to distinguish any minor source. In the case of an equal-ratio mixture of two sources, the $\mathrm{Sr}$ and $\mathrm{Nd}$ signature will be midway on a mixing line between the endmember source signatures. Also, there is evidence that Sr isotope signatures are subtly influenced by particle size fractionation processes, which occur during the long range transport of dust particles (Gaiero 2007).

In the case of $\mathrm{Sr}$ and $\mathrm{Nd}$ isotopes in interglacial Antarctic ice, there are indications of dust arriving from SSA, Antarctica and Australia. As shown in Figure $1 \mathrm{~A}$, the $\mathrm{Sr}$ and $\mathrm{Nd}$ signatures of interglacial dust have higher ${ }^{87} \mathrm{Sr} /{ }^{86} \mathrm{Sr}$ and lower ${ }^{143} \mathrm{Nd} /{ }^{144} \mathrm{Nd}$ ratios compared to signatures in glacial dust. Two potential source areas of dust deflation with compatible isotopic signatures include the Puna/Altiplano region in South America (Delmonte et al. 2010; Gaiero 2007), which is also considered the most likely
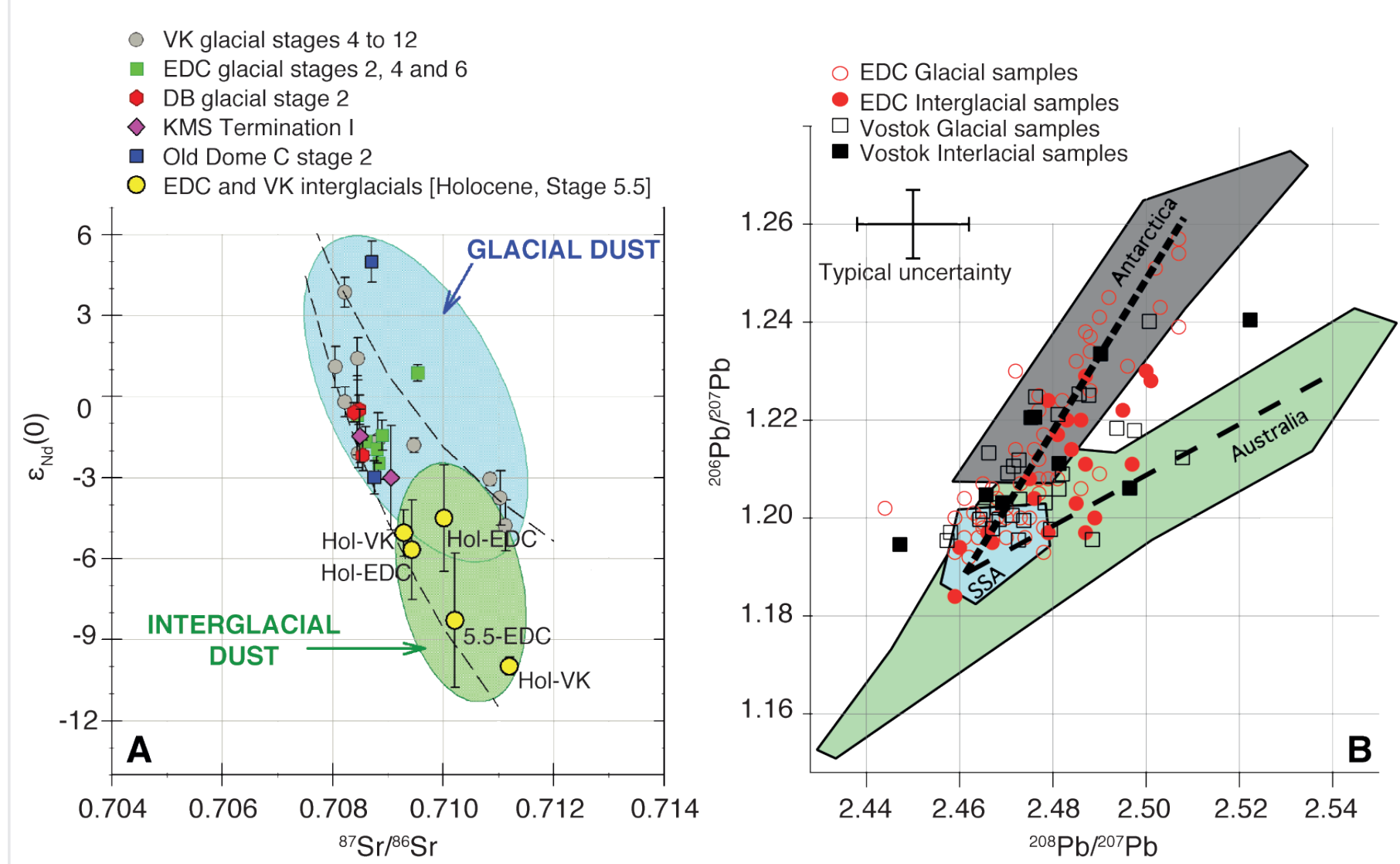

Figure 1: Strontium and Neodymium isotopes (A) and Lead isotopes (B) demonstrate changes in isotopic signature from glacial to interglacial periods. The identification of dust sources other than those of Southern South America is limited by measurement precision and the overlapping signatures of potential secondary dust source areas. Panel A modified from Delmonte et al. (2007). VK: Vostok; EDC: Epica Dome C; DB: Dome B; KMS: Komsomolskaya. 
secondary source during glacials, as well as the ephemerally watered basins of central (Lake Eyre) and southeast (Darling basin) Australia (De Deckker et al. 2010; and this issue). Bory et al. (2010) sampled large volumes of surface snow at Berkner Island, in the Atlantic sector of coastal Antarctica, for seasonal resolution of $\mathrm{Sr}$ and $\mathrm{Nd}$ isotopic compositions. The results confirmed SSA to be the dominant dust source but also suggested a variety of dust sources occurring without seasonal regularity. While the possibility of springtime dust inputs from Australia could not be excluded, the relatively high proportion of large $(>5 \mu \mathrm{m})$ dust particles found in the snow was indicative of dust from proximal deflation sources within Antarctica (see also Gili and Gaiero, this issue).

For $\mathrm{Pb}$ isotopes, the situation is complicated because volcanoes also emit $\mathrm{Pb}$, and hence in Antarctic ice, the $\mathrm{Pb}$ isotope data usually fall along a mixing line between the dominant dust source in SSA and the dominant volcanic $\mathrm{Pb}$ source attributed to Mt Erebus in Antarctica. Figure $1 \mathrm{~B}$ shows $\mathrm{Pb}$ isotope data from the EPICA Dome C (Vallelonga et al. 2010) and Vostok (unpublished data) ice cores. Rather than a random scattering around the mixing line between SSA Pb and Antarctic Pb, the data tend to have signatures indicative of a third source which matches the signature of dust samples from Australia and Antarctica. The improved identification of secondary dust sources in central Antarctica by $\mathrm{Pb}$ isotopes is also due, among other factors, to recent advances in instrumentation that now offers isotope ratio measurements with higher precision. For an even better result, it would be advantageous to apply such measurements to an ice core from a location where the interference of $\mathrm{Pb}$ from local Antarctic volcanism is minimized.

\section{Changes in the dust mix}

Despite the difficulties of identifying secondary sources of dust to Antarctica, indications are strong that the composition of dust deposited in Antarctic ice has varied, particularly during the LGM-Holocene transition 20 to $10 \mathrm{ka}$ ago. Indications of dust composition changes are found in a variety of indicators, particularly in trace element compositions, geochemistry and physical properties such as magnetic susceptibility and solubility. Siggaard-Andersen (2007) identified changes in the solubility of Lithium in EPICA Dome C (EDC) ice over the deglaciation, suggestive of a change of dust source(s) over that time. Marino et al. (2008) confirmed such indications by geochemical characterization of EDC dust, as well as suggesting an Australian dust source during interglacials. Albani et al. (2012) identified a deglacial change in dust particle size distributions at Talos Dome, in Northern Victoria Land. The shift toward larger dust particles at Talos Dome indicated that local dust sources in the Transantarctic Mountains were activated in the early Holocene.

Wegner and colleagues have reported the concentrations of Rare Earth Elements (REEs) in various Antarctic ice cores (Gabrielli et al. 2010; Wegner et al. 2012). Comparable to the $\mathrm{Sr}, \mathrm{Nd}$ and $\mathrm{Pb}$ isotopes, REEs are subject to fractionation as they have similar chemical

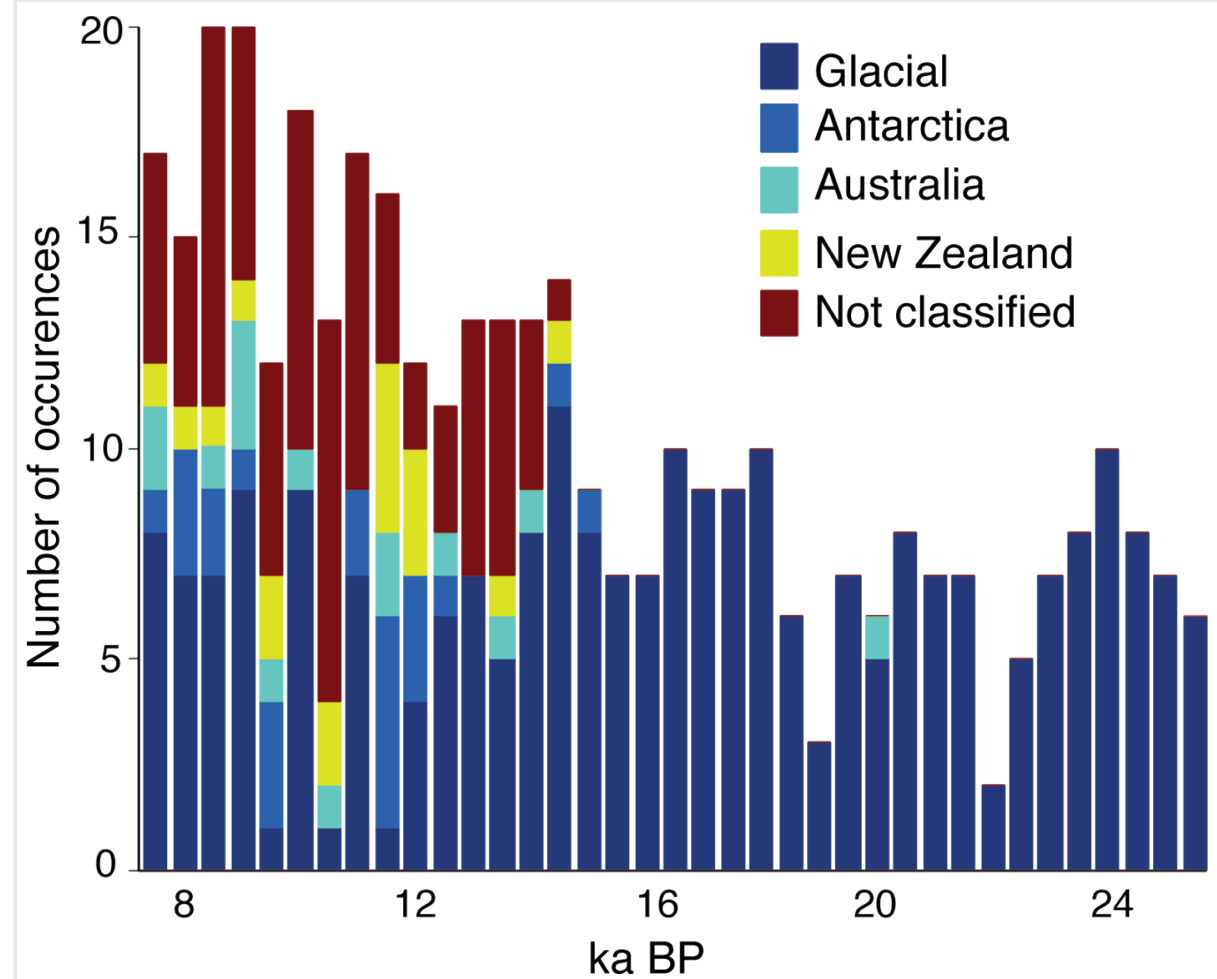

Figure 2: Histogram of REE patterns found in the EPICA Dronning Maud Land ice core over the last deglaciation clearly demonstrating the appearance of non-glacial dust types after $15 \mathrm{ka}$ BP. REE patterns were statistically attributed to dust from Antarctica, Australia and New Zealand. Modified after Wegner et al. (2012).

properties but range in atomic weight from 139 (Lanthanum) to 175 (Lutetium). Consequently, the REE compositions differ between dust deflation zones due to their specific geochemical histories. Wegner and colleagues identified a "glacial" REE signature in the EDML ice core: In addition, they differentiated four other REE types, which were observed only during the deglaciation after $\sim 15 \mathrm{ka}$ ago (Fig. 2) and were attributed to dust from Antarctica, Australia and New Zealand.

\section{Known unknowns of}

\section{intercontinental dust transport}

While there is only indirect evidence of early Holocene transport of Australian dust to Antarctica, unequivocal evidence of intercontinental dust transport in the late Holocene has been observed. Lead isotopic compositions in Law Dome ice show that anthropogenic Pb contamination of Antarctica began late in the 1880's (Vallelonga et al. 2002). Lead isotopes showed the pollution source to be the Broken Hill mine in Southeastern Australia - one of the known dust deflation zones of Australia. Broken $\mathrm{Hill} \mathrm{Pb}$ was released in the process of smelting Silver-Lead ores, first at Broken Hill (1887-1889) and later at Port Pirie in South Australia (1889 onwards). This demonstrates that aerosols can in principle be transported from Southeastern Australia to Antarctica, but the question remains as to whether anthropogenically-emitted $\mathrm{Pb}$ can be considered representative of naturally deflated mineral dust.

\section{Some ways forward}

Resolving the question of secondary dust sources in Antarctica is possible, but requires a cross-disciplinary approach, with further investigation of dust deflation zones, more precise analyses of dust in Antarctic ice, and enhanced understanding of the transport processes involved. Improved characterization of dust deflation zones will ensure that the source areas characterized accurately represent the deflated dust. Dust traps and airborne collection techniques can help with such efforts. Satellite observations can help understanding the dynamics of dust transport by tracking dust plumes from their continental sources all the way to Antarctica. New or improved analytical techniques may also enable better studies of the dust deposited in ice. Some techniques, such as $\mathrm{REE}$ or $\mathrm{Pb}$ isotope analysis, require larger datasets or more sensitive instrumentation, respectively. Finally, completely new approaches, such as Optically Stimulated Luminescence may offer a fresh approach to distinguish and apportion inputs of feldspar-rich SSA dust from quartz-rich Australian dust (Lepper et al. 2001).

\section{DATA}

Data presented in this article are available from the PANGAEA (www.pangaea.de) and NOAA paleoclimate (www.ncdc.noaa.gov/paleo) databases, except for the Vostok $\mathrm{Pb}$ isotope data (available from the author).

\section{AFFILIATIONS}

Centre for Ice and Climate, University of Copenhagen, Denmark

\section{CONTACT}

Paul Vallelonga: ptravis@nbi.ku.dk

\section{REFERENCES}

Full reference list under:

www.pages-igbp.org/products/magazine/ref2014_2.pdf

De Deckker P et al. (2010) Palaeogeog Palaeoclimatol Palaeoecol 285: 205-223

Delmonte B et al. (2008) Geophys Res Lett 35, doi:10.1029/2008GL033382

Lambert F et al. (2008) Nature 452: 616-619

Vallelonga P et al. (2010) Quat Sci Rev 29: 247-255

Wegner A et al. (2012) Clim Past 8: 135-147 